\title{
Management of Type 2 Diabetes - Methods for Addition of Prandial to Basal Insulin
}

\author{
Helena W Rodbard ${ }^{1}$ and Boris Karolicki² \\ 1. Medical Director, Endocrine and Metabolic Consultants, Rockville, Maryland, US; 2. Medical Director, Novo Nordisk Inc., Princeton, New Jersey, US
}

\begin{abstract}
As glycaemic control deteriorates with the progression of type 2 diabetes, treatment guidelines advocate starting basal insulin therapy, and then progressing to a basal-bolus regimen as needed. Nevertheless, although timely intensification of therapy is important to minimise the risk of diabetic complications, considerable clinical inertia exists, not only in the initiation of insulin but also in the progression to multiple-dose insulin regimens. One barrier has been the lack of guidance about how to make the transition from basal-only to basal-bolus insulin therapy. In this review, we discuss how data from the recent FullSTEP study, along with other randomised studies, will help to bridge this gap. Prandial boluses can be added to basal insulin in a stepwise manner, using a straightforward, patient-led dose titration approach and simple estimation of which meal to add the initial prandial bolus to. Reducing the complexity of progression to multiple-dose insulin regimens and empowering patients will lessen the burden on clinicians, improve treatment satisfaction and facilitate timely implementation of treatment guidelines.
\end{abstract}

\section{Keywords}

Type 2 diabetes, stepwise, basal-bolus, insulin, treatment intensification, patient satisfaction, self-titration

Disclosure: Helena W Rodbard has served as a principal investigator in clinical trials sponsored by Novo Nordisk, has served as a consultant on advisory panels and as a speaker for Novo Nordisk and has served in similar capacities for several pharmaceutical companies that have or are developing various forms of insulin therapy. Boris Karolicki is employed by Novo Nordisk Inc. as a Medical Director for modern insulins and insulin-delivery devices.

Acknowledgements: The FullSTEP trial was sponsored by Novo Nordisk. Writing and editorial support for the preparation of this manuscript was provided by Watermeadow Medical (sponsored by Novo Nordisk).

Received: 30 July 2014 Accepted: 8 August 2014 Citation: European Endocrinology, 2014;10(2):124-30 DOI:10.17925/EE.2014.10.02.124

Correspondence: Helena W Rodbard, Endocrine and Metabolic Consultants, 3200 Tower Oaks Boulevard, Suite 250, Rockville, Maryland, 20852, US. E: hrodbard@comcast.net

Support: The publication of this article was supported by Novo Nordisk. The views expressed are those of the authors and not necessarily those of Novo Nordisk.

\section{Insulin Use - Trends and Barriers}

Of "theoretically unlimited efficacy": the American Diabetes Association (ADA) and the European Association for the Study of Diabetes (EASD) summarise one advantage of insulin for the treatment of type 2 diabetes (T2D). ${ }^{1}$ Counterpoint disadvantages, most prominently hypoglycaemia, are diminished with the use of insulin analogues in comparison with human insulin. ${ }^{1-5}$ The ADA, EASD and the American Association of Clinical Endocrinologists (AACE) recommend that patients with T2D start combination therapy that includes insulin either initially or upon deterioration of glycaemic control, depending on the level of haemoglobin $\mathrm{A} 1 \mathrm{C}\left(\mathrm{HbA}_{1 \mathrm{c}}\right)$ and individualised considerations. ${ }^{1,6-9}$ In the UK, for example, the number of people using insulin increased threefold between 1991 and 2010; the estimated proportion of people with T2D using insulin increased from $5 \%$ to $15 \%$ over the same period. ${ }^{10}$ Whereas increasing prevalence of T2D in part drives the increase in the absolute number of insulin users, the introduction of insulin analogues may contribute to the proportional increase in use. ${ }^{10}$

And yet the data showing an upward trend for the use of insulin in T2D in the UK between 1991 and 2010 also reveal that the increase plateaued after 2005, with a small decline in the final years of the study. As well as reflecting the increased use of glucagon-like peptide-1 (GLP-1) receptor antagonists, this plateau effect may be attributable to delayed insulin initiation. ${ }^{10}$ Worldwide, the introduction and modification of insulin regimens in practice is frequently delayed compared with treatment guidelines." Uncontrolled diabetes raises patients' risk of diabetic complications. ${ }^{12-15}$

Research into overcoming barriers to insulin use has mostly focused on initiation. ${ }^{16}$ Educating patients and clinicians to reduce misconceptions about insulin use, and creating approaches that are straightforward to implement in primary care are emergent strategies. Less attention has been paid to inertia in the intensification of insulin therapy but many of the same needs are apparent. ${ }^{11,17}$ Intensification is widely perceived as the "preserve of specialists", 16 in part because there are no guidelines that specifically address the intensification of insulin therapy from basal-only to basal-bolus.

\section{Recommended Insulin Therapy}

A single daily dose of basal insulin added to existing oral antidiabetic drug (OAD) therapy is the most convenient way to start insulin therapy, with the addition of prandial coverage to be considered in the advent of uncontrolled postprandial plasma glucose (PPG) excursions. Although the AACE, ADA and EASD all stress the importance of making individualised therapy choices, their guidelines/algorithm state that, when this step becomes necessary, a basal-bolus insulin regimen offers the most precise and flexible prandial coverage. ${ }^{1.6,7}$ These organisations also recommend a gradual progression from basal-only insulin therapy 
to a basal-bolus regimen, and emphasise the importance of selfmonitoring of blood glucose (SMBG) for dose titration.

\section{The Need for FullSTEP}

Aiming to provide practical support to assist implementation of the ADAEASD position statement, the FullSTEP study was reported in $2014 .{ }^{18}$ FullSTEP was the first randomised clinical trial (RCT) to compare patientled management of two approaches to the addition of prandial to basal insulin. The study compared stepwise addition of insulin boluses to basal insulin with immediate transition to a full basal-bolus regimen. The purpose of this review is to outline the clinical needs that underpin the rationale for the FullSTEP study, to discuss the study design and key findings, and to explore the implications for clinical practice.

\section{Glycaemic Control and Diabetic Complications Long-term Consequences of Dysglycaemia}

Normalising blood glucose ameliorates the long-term complications of diabetes, as first convincingly demonstrated by the Diabetes Control and Complications Trial (DCCT) in patients with type 1 diabetes. ${ }^{19}$ Intensive treatment targeting near-normal glucose metabolism reduced microvascular complications in type 1 diabetes in comparison with standard treatment. ${ }^{19}$ The subsequent Epidemiology of Diabetes Interventions and Complications (EDIC) observational follow-up study has demonstrated that the benefits of tight glycaemic control during the DCCT trial period persist for decades and result in substantial reduction of macrovascular disease. ${ }^{13}$ Mean (SD) $\mathrm{HDA}_{1 \mathrm{c}}$ in the DCCT intensive treatment group was 7.2 (0.9) \% at study end compared with 9.1 (1.3) \% in the standard group. By the 18-year follow-up point, these levels had converged to $8.0(1.0) \%$ in both groups, but patients in the intensive treatment group had fewer complications. ${ }^{13}$

In T2D, the UK Prospective Diabetes Study (UKPDS) and associated long-term follow-up studies also showed long-term reduction of both micro- and macrovascular disease with intensive glycaemic control. ${ }^{12,20-23}$ The Kumamoto study in Japanese patients with T2D demonstrated that intensive glycaemic control delayed the onset and progression of microvascular complications. ${ }^{14}$

\section{Pathological Mechanisms and the Role of Postprandial Plasma Glucose}

The 'metabolic memory' effect is thought to derive from hyperglycaemia-driven excess of reactive oxygen species, which activate signalling pathways and initiate self-perpetuating metabolic effects that may become irreversible even if excellent glycaemic control is re-established. ${ }^{24,25}$ Some discrepancies exist in the clinical data relating glycaemic control to macrovascular complications of diabetes, which have been attributed to insufficient follow-up periods, different patient populations and the confounding effects of pre-trial glycaemic exposure. ${ }^{24-26}$ Another potential confounder is the influence of glycaemic variability, including postprandial excursions. Oscillations in blood glucose might have a greater role than overall levels of glycaemia in generating damaging oxidative stress. ${ }^{27}$ As investigations into these mechanisms continue, the general importance of minimising fasting as well as postprandial hyperglycaemia is well accepted. ${ }^{1,24}$

\section{Glycaemic Targets}

Management recommendations and glycaemic targets are periodically modified as new data emerge. ADA-EASD and the International Diabetes Federation (IDF) advocate an $\mathrm{HbA}_{1 \mathrm{c}}$ target of $<7.0 \%$ in most patients. ${ }^{1.89}$ This goal leaves a gap from the threshold of $\mathrm{HbA}_{1 \mathrm{c}} \geq 6.5 \%$ for the diagnosis of $\mathrm{T} 2 \mathrm{D}_{1}{ }^{28}$ but reflects that more stringent targets might increase the risk of hypoglycaemic events. In younger individuals with disease of short duration, lower targets can be set. Conversely, targets of 7.5-8.0 \% or more are appropriate for some people. $1.7,9$ AACE guidelines suggest a goal of $\leq 6.5 \%$ for healthy patients at low risk of hypoglycaemia, with higher thresholds when appropriate. All of these associations recommend individualisation of glycaemic targets. ${ }^{1,-9}$

\section{Fasting versus Postprandial Glycaemia}

$\mathrm{HbA}_{1 \mathrm{C}}$ levels reflect the average, integrated contribution of fasting plasma glucose (FPG) and PPG levels. The relative contributions of these two aspects of glycaemic control, and how they should be prioritised in management strategies, are less well established. In 2003, Monnier et al..$^{29}$ reported that, at the lower end of the $\mathrm{HbA}_{1 \mathrm{c}}$ scale $(<7.3 \%$ in insulin-naive patients, PPG contributed roughly $70 \%$ of excess glycaemia. At higher $\mathrm{HbA}_{1 \mathrm{c}}$ levels, FPG accounted for an increasing proportion of the dysglycaemia. Above $\mathrm{HbA}_{10}$ levels of $10.2 \%$, FPG levels accounted for roughly $70 \%$ of hyperglycaemia. This pattern is thought to reflect the progressive nature of T2D attributable to a gradual decline of $\beta$-cell function with increasing dysglycaemia. ${ }^{30}$ Accordingly, as therapy reduces $\mathrm{HbA}_{1 \mathrm{c}}$ to near-normal levels, postprandial hyperglycaemia becomes an important 'rate-limiting factor' in achieving target levels of glycaemic control. ${ }^{31}$

\section{Postprandial Plasma Glucose as a Therapeutic Target}

Reduction of postprandial hyperglycaemia is a high priority when $\mathrm{HbA}_{1 \mathrm{C}}$ levels are at or near target. However, elevated postprandial glucose may also influence vascular pathology at all $\mathrm{HbA}_{1 \mathrm{c}}$ levels. ${ }^{27}$ Overall glycaemic variability encompasses PPG peaks combined with the effects of hypoglycaemia, and has been implicated in long-term diabetic complications. In one study of patients with T2D and chest pain, the mean amplitude of glycaemic excursions (MAGE) was greater in those with coronary artery disease than in those without. ${ }^{32}$

Long-term data are needed to establish whether PPG and/or glycaemic variability are independent risk factors for diabetic complications. Postprandial hyperglycaemia is an integral part of overall glycaemic exposure. The ADA guidelines indicate that lowering PPG to $<180 \mathrm{mg} / \mathrm{dl}$ $(<10.0 \mathrm{mmol} / \mathrm{l})$ is a reasonable treatment strategy to optimise glycaemic control if $\mathrm{HbA}_{1 \mathrm{c}}$ levels remain above target despite target levels of premeal glucose. ${ }^{.}$Similarly, IDF guidelines describe the case for targeting PPG as compelling, and note that an $\mathrm{HbA}_{1 \mathrm{c}}$ level of $7.0 \%$ translates to target PPG levels of $<9.0 \mathrm{mmol} / \mathrm{l}(<160 \mathrm{mg} / \mathrm{dl})$.

\section{Insulin Therapy}

T2D is a progressive disease that results in an incremental approach to treatment. Metformin is the first-line pharmacological therapy for most patients. Insulin can be started from the outset in the presence of marked or symptomatic hyperglycaemia, either in combination with OADs or as monotherapy. ${ }^{1,89}$ For patients who start with metformin therapy, a second $O A D$, a GLP-1 receptor agonist or insulin can be added after 3 months if $\mathrm{HbA}_{1 \mathrm{c}}$ levels remain elevated. ${ }^{1,2}$ If individualised targets are not achieved over an additional 3-month period, one can advance to triple therapy. Most patients will ultimately require insulin to achieve and maintain the desired level of glycaemic control. ${ }^{1,2}$

\section{Basal Insulin}

Basal insulin is the standard approach for initiating insulin therapy after the failure of OADs, as shown in the 1-year ${ }^{33}$ and 3-year results from the Treat to Target in Type 2 Diabetes (4-T) study. ${ }^{34}$ Similar mean $\mathrm{HbA}_{1 \mathrm{C}}$ levels were achieved at the end of the study whether patients 
started on basal, biphasic or prandial insulin, but a higher percentage of patients in the initial basal insulin group reached $\mathrm{HbA}_{1 \mathrm{c}}<6.5 \%$ compared with the biphasic group (44.7\% versus $31.9 \%$; $=0.006$ ), hypoglycaemia was lower in the basal insulin group than in the prandial or biphasic group, and weight gain was lowest in the basal insulin group. A larger proportion of patients in the basal insulin group added a second type of insulin due to inadequate glycaemic control during the study (81.6 \%) compared with the biphasic (67.7\%) or prandial group (73.6\%; $\mathrm{p}=0.002$ for the overall comparison). ${ }^{34}$ The major advantage of initiating with basal insulin only is the simplicity of the regimen. This gives the physician and/or the patient time to learn how to titrate therapy, and also minimises the need for SMBG.

\section{Insulin is Underused}

Insulin treatment can be initiated at any point in the course of T2D. Early initiation of insulin and improved glycaemic control may help to preserve $\beta$-cell function, promote vascular endothelial health and minimise the risk of complications, although long-term clinical data are needed to clarify these potential associations. ${ }^{35}$ Nevertheless, rather than occurring early in treatment progression, initiation and intensification of insulin regimens in practice is often delayed in the face of poor or worsening glycaemic control..$^{11,35}$

\section{Barriers and Patient Empowerment}

In 2005, the Diabetes Attitudes, Wishes, and Needs (DAWN) study showed that $50-55 \%$ of nurses and general practitioners delayed starting insulin. ${ }^{36}$ The perceptions of both patients and of healthcare providers present barriers to initiating therapy. To some patients, insulin is a mark of personal failure. Physicians may be concerned with the potential for hypoglycaemia, or the lack of resources to help a patient establish an appropriate regimen..$^{16}$ Education to overcome such anxieties and empower patients to improve their glycaemic control is a key priority. When discussing therapy with patients, efforts to ease injection-related worries might serve their interests better than accommodating those anxieties in choice of therapy. Furthermore, whereas educating patients to self-titrate their insulin dose has the obvious advantage of reducing the need to meet with healthcare practitioners as often, patient-driven insulin titration regimens also make individuals feel involved in their treatment and can enhance glycaemic control. $16,37,38$ Benefits of self-titration of basal (and, to some extent, premix) insulin regimens have been shown, although more clinical data are required regarding diabetes education programmes and the optimal use of self-management algorithms. ${ }^{37}$

\section{Intensification of Insulin Therapy Beyond Basal Insulin}

If therapy with basal insulin fails to achieve the desired target $\mathrm{HbA}_{1 \mathrm{c}}$ levels, the more complex insulin strategies should be implemented. ${ }^{1.8}$ For example, as mentioned above, $81.6 \%$ of patients who started using basal-only insulin in the $4 \mathrm{~T}$ study required the addition of another insulin by study end. ${ }^{34}$

The two major pathways of insulin intensification are use of basal-bolus insulin and use of premixed insulins. Premixed insulin formulations may offer comparable efficacy to basal-bolus insulin, with a regimen that suits some patients. Other people find the fixed ratio of the shorter- and longeracting components to be too inflexible for fine-tuning glycaemic control, as it prevents separate titration of each component of the insulin. ${ }^{1}$

\section{Barriers to Insulin Intensification}

There is limited research in terms of the barriers to insulin intensification. Injection-related concerns are diminished in those with insulin experience, ${ }^{17}$ but appropriate progression of treatment is frequently delayed in practice. ${ }^{11}$ Physicians' concerns about complex insulin regimens include their patients' coping abilities, but they also worry whether they themselves have sufficient understanding of the requirements, including how best to help their patients through the process. In this regard, a key unmet need is the lack of clear algorithms to guide patient-led treatment progression. Barriers attributed to physicians also include patient non-compliance and comorbid health concerns, as well as lack of time. The potentially increasing imposition of treatment on daily life is a concern of some patients with T2D. ${ }^{16,17}$

Concerns about the need for increased frequency of SMBG are part of this perceived imposition, and can impede intensification of insulin therapy. In a survey of 886 patients with T2D, however, burden (day-to-day practicality) was not an obstacle to effective SMBG and adjustment of insulin dose, whereas the psychological factors avoidance and pointlessness were independent predictors of self-monitoring behavioural measures. ${ }^{39}$ Enabling patients to understand the benefits of active adjustment of insulin regimens might mitigate a substantial barrier to their use.

Adherence to insulin regimens can also be suboptimal: a systematic review found self-reported rates of $43-86 \%{ }^{40}$ Factors affecting adherence were not consistent between the available studies, although a flexible regimen that can be incorporated into patients' lifestyles might improve adherence to therapy. ${ }^{40}$

\section{Basal-plus Approaches}

Patients for whom basal insulin is or becomes insufficient for maintaining glycaemic control require the addition of prandial insulin. Adding a single bolus dose to the main meal or to breakfast is known as the 'basal-plusone' approach. ${ }^{41}$ In a 2011 phase IV 'proof-of-concept' study, Owens et al. determined basal-plus-one to be "a logical next step" after a basal-only regimen, finding significant but modest improvements in $\mathrm{HbA}_{1 c^{\prime}}$ without increased hypoglycaemia or weight gain. The investigators suggested that basal-plus regimens might provide a bridge toward full basal-bolus therapy - as with basal-only regimens, basal-plus therapy fails to establish lasting glycaemic control in many patients. ${ }^{42}$ Since then, other studies have examined basal-plus approaches to insulin intensification, but (apart from the Self-Titration with Apidra to Reach Target [START] trial, which is discussed in the context of patient-led dose titration during treatment intensification below), we focus here on trials involving multiple daily prandial insulin doses.

\section{Stepwise Approaches}

A few RCTs of approaches to the incorporation of multiple daily bolus doses into insulin treatment regimens were done before the FUllSTEP study, but all involved physician-led insulin dose titration. ${ }^{42-47}$ The implications of these studies are briefly discussed here, and are also considered in the primary FullSTEP study report. ${ }^{18}$

In the 48-week Step-wise RCT, a bolus dose of insulin aspart was incrementally added to basal insulin detemir for each 12-week phase that ended in inadequate glycaemic control $\left(\mathrm{HbA}_{1 \mathrm{c}} \geq 7.0 \%\right){ }_{.}{ }^{43}$ The study compared two ways to choose which meal to add the next bolus to: in the ExtraSTEP group ( $n=146)$, the PPG increment was measured; whereas in the SimpleSTEP group ( $n=150)$, meal size was determined by the patient. Overall, $\mathrm{HbA}_{1 \mathrm{c}}$ levels were reduced by approximately $1.2 \%$. Most of the glycaemic effect was observed with addition of the first two boluses, but approximately $75 \%$ of patients required three daily prandial insulin injections by study end. Results were comparable 
in the two groups, demonstrating that boluses can be added to meals according to the patient's perception of the size of the meal.

The Step-wise study did not compare the efficacy and safety of incremental addition of bolus doses with immediate progression to full basal-bolus therapy ${ }_{1}{ }^{33}$ a comparison that was made in the Opposing Step-by-step Insulin Reinforcement to Intensified Strategy (OSIRIS) RCT. ${ }^{47}$ In OSIRIS, patients with poorly controlled T2D at the end of a 6-month run-in period using basal insulin glargine were randomised to full basal-bolus therapy (three daily doses of bolus insulin glulisine) or to stepwise addition of insulin glulisine (with or without an insulin secretagogue). The primary study objective, to show non-inferiority of the stepwise approaches compared with full basal-bolus therapy, was not achieved, which was partly attributed to lack of patient and/or investigator adherence to the study protocol. Subgroup analysis showed that the primary objective was met in patients with $\mathrm{HbA}_{10}$ $\leq 8 \%$ at randomisation. Significantly less weight gain was observed with the stepwise approach in comparison to full basal-bolus therapy with four injections per day. Use of the insulin secretagogue did not enhance results of the stepwise regimen. ${ }^{47}$

Starting with three versus fewer than three daily bolus insulin doses was also investigated in a study by Davidson et al. ${ }^{48}$ After run-in treatment with insulin glargine, patients with $\mathrm{HbA}_{1 \mathrm{c}}>7.0 \%$ were randomised to receive one, two or three bolus doses of insulin glulisine per day. Onceand twice-daily prandial doses were non-inferior to three times a day in terms of glycaemic control, but the study did not address the incremental addition of bolus doses within individual patients. ${ }^{48}$

Results from the All to Target trial, which compared the physicianmanaged introduction of three different complex insulin regimens in patients not previously using insulin, were published shortly after the FullSTEP study. ${ }^{49}$ Alongside a premix insulin group, two groups used basal insulin glargine, one of them with a single daily bolus dose of insulin glulisine and the other with sequential addition of up to three bolus doses. The insulin-glargine-based regimens enabled more patients to achieve $\mathrm{HbA}_{1 \mathrm{c}}<7.0 \%$ compared with the premix group, but were not significantly different from one another.

\section{The FullSTEP Study}

\section{Aims of FullSTEP}

The FullSTEP study investigated the efficacy and safety of stepwise addition of bolus insulin doses to basal insulin therapy compared with an immediate transition to full basal-bolus therapy. A key aspect of FullSTEP was to enable the patients to make their own insulin adjustments. As discussed in the following sections, intensification of insulin treatment in FullSTEP - that is, whether to add another bolus dose - was decided by the physician on the basis of $\mathrm{HbA}_{1 \mathrm{c}}$ level $(\geq 7.0 \%$ ), but titration of the bolus insulin doses was led by the patients. The data will consequently reassure physicians that patients can handle the requirements of self-managed insulin dose titration; further, they demonstrate that insulin intensification can be undertaken in a real-world setting that minimises the pressure on healthcare resources. The active involvement of patients, empowering them to manage their treatment, will also mitigate some of the patientattributed barriers to intensification of insulin therapy discussed above.

\section{Study Design and Patient Characteristics}

The FullSTEP study involved 150 sites across seven countries in Europe and the Americas. ${ }^{18}$ The inclusion criteria were: adult patients with T2D of at least 12 months' duration and using basal insulin for $\geq 6$ months; $\mathrm{HbA}_{10}$ 7-9 \%; body mass index (BMI) $<40 \mathrm{~kg} / \mathrm{m}^{2}$ and willingness to comply with
SMBG, injection regimens and self-titration algorithms, as well as eating at least three meals per day. Concomitant metformin and/or pioglitazone therapy was continued during the randomised treatment phase, whereas treatment with insulin secretagogues, dipeptidyl peptidase-4 inhibitors and $\alpha$-glucosidase inhibitors was discontinued. Patients switched to once-daily basal insulin detemir (at bedtime) if not using it already.

After completing an 8-week run-in period using insulin detemir, 401 patients were randomised to the stepwise $(n=201)$ and basal-bolus $(n=200)$ treatment groups. Randomisation was stratified according to $\mathrm{HbA}_{1 \mathrm{C}}$ level (7.0-8.0\% and 8.1-9.0\%, respectively), with mean (SD) $\mathrm{HbA}_{1 \mathrm{C}}$ of 7.9 (0.6) \% in both treatment groups. Other mean baseline characteristics were similar between the groups, including age (60.0 and 59.6 years), BMl (31.5 and $30.7 \mathrm{~kg} / \mathrm{m}^{2}$ ) and duration of diabetes (12.8 and 12.5 years).

Thereafter, a 32-week treatment phase was divided into three periods. Initially, patients in the stepwise group added one bolus insulin aspart dose to the meal they considered the largest of the day (estimated as having the highest carbohydrate content). In this group, second and third boluses were added to the next largest meals at the end of subsequent treatment periods (that is, at weeks 11 and 22) if the goal of $\mathrm{HbA}_{1 \mathrm{c}}<7.0 \%$ was not met. Patients in the basal-bolus group received insulin aspart before each of three daily meals throughout the treatment phase.

\section{Dose Titration and Assessment of Outcomes}

The starting dose of insulin detemir was determined by the average pre-breakfast SMBG level from 3 consecutive days in the week prior to the start of the run-in phase. For patients with SMBG $<7.2 \mathrm{mmol} / \mathrm{l}$ $(130 \mathrm{mg} / \mathrm{dl})$, the starting dose of insulin detemir was equal to the pretrial insulin dose. For those with SMBG $>7.2 \mathrm{mmol} / \mathrm{l}(130 \mathrm{mg} / \mathrm{dl}), 3 \mathrm{U}$ were added to the previous dose.

During the run-in phase, patients self-managed the titration of their basal insulin dose, adjusting it as necessary every 3 days. ${ }^{18}$ The mean value of pre-breakfast SMBG readings from the 3 preceding days was used: the dose was either unchanged or adjusted up or down by $3 U-a$ '30-3' algorithm (see Table 1). Study investigators reviewed the patients' basal insulin dose adjustments on a weekly basis. If titration of the basal insulin dose was required during the treatment phase, it was managed by the physician.

Throughout the treatment phase, patients in both groups self-titrated their bolus insulin doses on a daily basis. Each dose was independently adjusted according to the relevant SMBG reading from the previous day. Patients in the stepwise group started with $4 \mathrm{U} /$ day in a single bolus dose. They were also checking their SMBG twice daily, including the pre-breakfast level. The timing of the second daily SMPG measurement was determined by which meal the bolus dose was taken at. To titrate a breakfast-time bolus dose, the pre-lunch SMPG level from the previous day was used; for a lunchtime dose, the pre-dinner value from the day before was used; and, for a dinnertime dose, the bedtime level from the day before was used. Therefore, if a patient in the stepwise group had a second and/or third daily bolus dose added at the end of a treatment period, they needed to also add third and/or fourth daily SMBG measurements. Accordingly, patients in the basal-bolus group recorded four SMBG readings daily throughout the treatment phase. In both groups, each bolus dose was adjusted up or down by $1 \mathrm{U} /$ day, or unchanged - following a '1-0-1' algorithm (see Table 1).

The primary outcome in the FullSTEP study was non-inferiority of the stepwise approach compared with the full basal-bolus regimen, as 


\section{Table 1: Algorithms Used in Studies of Patient-led Insulin Treatment Intensification}

\begin{tabular}{|c|c|c|c|c|c|}
\hline \multirow[t]{2}{*}{ Study } & \multirow[t]{2}{*}{ Insulin Regimens Studied } & \multirow[t]{2}{*}{ Insulin Type } & \multirow[t]{2}{*}{ Management of Titration } & \multicolumn{2}{|c|}{ Algorithms for Patient-managed Dose Titration } \\
\hline & & & & $\begin{array}{l}\text { Glucose Reading } \\
\mathrm{mmol} / \mathrm{l}(\mathrm{mg} / \mathrm{dl})\end{array}$ & Dose Adjustment, $\mathrm{U}^{*}$ \\
\hline $\begin{array}{l}\text { Rodbard: FullSTEP18 } \\
\text { NCT01165684 }\end{array}$ & $\begin{array}{l}\text { Progression from basal-only to } \\
\text { basal-bolus therapy, in either a } \\
\text { stepwise or immediate manner }\end{array}$ & $\begin{array}{l}\text { Basal: insulin } \\
\text { detemir } \\
\text { Bolus: insulin } \\
\text { aspart }\end{array}$ & $\begin{array}{l}\text { By patient during run-in period; } \\
\text { by physician if necessary during } \\
\text { treatment phase } \\
\text { By patient }\end{array}$ & $\begin{array}{l}>7.2(>130) \\
4.0-7.2(71-130) \\
\leq 3.9(\leq 70) \\
>7.2(>130) \\
4.0-7.2(71-130) \\
\leq 3.9(\leq 70)\end{array}$ & $\begin{array}{l}+3 \\
0 \\
-3 \\
+1 \\
0 \\
-1\end{array}$ \\
\hline $\begin{array}{l}\text { Harris: START }{ }^{52} \\
\text { NCT01013571 }\end{array}$ & $\begin{array}{l}\text { Progression from basal-only } \\
\text { to basal-plus therapy }\end{array}$ & $\begin{array}{l}\text { Basal: insulin } \\
\text { glargine } \\
\text { Bolus: insulin } \\
\text { glulisine }\end{array}$ & $\begin{array}{l}\text { By patient during run-in period; } \\
\text { fixed during treatment phase } \\
\text { By patient (versus by physician) }\end{array}$ & $\begin{array}{l}>5.5(>99) \\
>8.0(>144) \\
5.0-8.0(90-144) \\
<5.0(<90)\end{array}$ & $\begin{array}{l}+1 \\
+1 \\
0 \\
-1\end{array}$ \\
\hline $\begin{array}{l}\text { Edelman: } \\
\text { Autonomy }\end{array}$ & $\begin{array}{l}\text { Progression from basal-only to } \\
\text { basal-bolus therapy, in a }\end{array}$ & $\begin{array}{l}\text { Basal: insulin } \\
\text { glargine }\end{array}$ & By physician & NA & \\
\hline NCT01215955 & stepwise manner & $\begin{array}{l}\text { Bolus: insulin } \\
\text { lispro }\end{array}$ & $\begin{array}{l}\text { By patient: daily schedule } \\
\text { By patient: 3-day schedule* }\end{array}$ & $\begin{array}{l}>6.3(>114) \\
4.7-6.3(85-114) \\
3.1-6.3(56-84) \\
<3.1(<56) \\
>8.0(>145) \\
6.4-8.0(115-144) \\
4.7-6.3(85-114) \\
3.1-6.3(56-84) \\
<3.1(<56)\end{array}$ & $\begin{array}{l}+1 \\
0 \\
-1 \\
-2 \\
+4^{\star} \\
+2^{\star} \\
0^{*} \\
-2^{*} \\
-4^{*}\end{array}$ \\
\hline
\end{tabular}

*All dose adjustments are daily, except for the 3-day schedule in the Study of Insulin Lispro in Participants With Inadequately Controlled Type 2 Diabetes (AUTONOMY) study. Details omitted for brevity include exceptions in the event of episodes of hypoglycaemia, and the timing and number of self-monitored blood glucose readings used for each adjustment.

assessed by change in $\mathrm{HbA}_{1 \mathrm{C}}$ from baseline to 32 weeks. The non-inferiority margin was set, in accordance with US Food and Drug Administration (FDA) guidance, ${ }^{50}$ at $0.4 \%$. FPG and 7-point SMBG profiles after each treatment phase were the secondary efficacy assessments. Doses of basal and prandial insulin were recorded; hypoglycaemic episodes, adverse events, and changes in body weight and BMl were monitored. The Diabetes Medical Satisfaction (DiabMedSat) ${ }^{51}$ questionnaire was used to assess treatment satisfaction..$^{18}$

\section{Non-inferiority of Stepwise Approach}

In the stepwise group, change in $\mathrm{HbA}_{1 \mathrm{c}}$ from baseline to 32 weeks was $-0.98 \%$ (95\% confidence interval [Cl] $-1.09 ;-0.87)$ compared with $-1.12 \%$ in the basal-bolus group ( $95 \% \mathrm{Cl}-1.23 ;-1.00)$. The mean treatment difference of $0.14(95 \% \mathrm{Cl}-0.02 ; 0.30 ; \mathrm{p}=0.0876)$ was within the non-inferiority margin; thus, stepwise addition of prandial insulin aspart boluses was shown to be non-inferior to full basal-bolus therapy.

\section{Glycaemic Control}

By study end, $55.9 \%$ of patients in the stepwise group and $63.3 \%$ of patients in the basal-bolus group had reached target $\mathrm{HbA}_{1 \mathrm{c}}<7.0 \%$ $(p=0.15)$. Changes in $\mathrm{HbA}_{1 \mathrm{c}}$ were significantly smaller at weeks 11 and 21 in the stepwise group compared with the basal-bolus group, but at the end of the study, there was no significant difference in $\mathrm{HbA}_{1 \mathrm{c}}$ reduction between the groups (see Figure 1). At the end of the trial, mean FPG was similar in the two groups (stepwise $7.12 \mathrm{mmol} / \mathrm{l}[95 \% \mathrm{Cl} 6.79 ; 7.46]$, basal-bolus $7.01 \mathrm{mmol} / \mathrm{l}$ [95 \% Cl 6.66;7.35]; $\mathrm{p}=0.64$ for mean treatment difference). Although mean PPG increments were significantly higher in the stepwise group (mean treatment difference $0.36 \mathrm{mmol} / \mathrm{l}[95 \% \mathrm{Cl}$ $0.01 ; 0.71] ; p=0.0459$ ), the mean 7-point SMBG profiles were similar at four time points between the two groups. Small differences were noted in the after-breakfast, before-lunch and before-bedtime values probably because at study end in the stepwise group, $17 \%$ of patients were still on only one prandial insulin dose per day, and $27 \%$ were on two. These patients would not be expected to achieve as much improvement in their SMBG profiles as patients using the full basal-bolus regimen, who experienced rapid control of all prandial excursions from the start of the trial. ${ }^{18}$

\section{Tolerability and Insulin Dose}

Hypoglycaemia rates in the basal-bolus group increased rapidly between weeks 0 and 10, and seemed to decline slightly during the remainder of the trial (see Figure 2). In the stepwise treatment group, the rate of hypoglycaemia increased slightly over the first 10 weeks, reduced over the duration of the second treatment period (weeks 10-21), then remained stable for the remainder of the trial (see Figure 2). Patients in the stepwise group had fewer overall hypoglycaemic episodes than did those in the basal-bolus treatment group (relative risk [RR]: 0.58 [95 \% Cl 0.45;0.75]; $p<0.0001$ ).

At study end, the mean daily basal insulin dose was $0.6 \mathrm{U} / \mathrm{kg}$ in both groups, with mean daily insulin aspart doses of $0.5 \mathrm{U} / \mathrm{kg}$ in the stepwise group and $0.6 \mathrm{U} / \mathrm{kg}$ in the basal-bolus group. Mean body weight increased slightly in both groups, with no significant treatment difference. Treatment-related adverse events did not differ between the groups. ${ }^{18}$

Fewer patients withdrew from the stepwise group compared with the basal-bolus group (25 versus 51 from the safety analysis set [patients exposed to study drug]). Determinants of study withdrawal did not follow a particular pattern, but adherence to therapy was better in the stepwise group, possibly reflecting greater treatment satisfaction (discussed next). ${ }^{18}$

\section{Patient Satisfaction}

DiabMedSat questionnaire results revealed an overall significantly greater degree of contentedness with treatment in the stepwise group (71.75 [95 \% Cl 69.93; 73.58]) compared with the basal-bolus group (68.16 [95 \% Cl 66.29; 70.03]); a mean treatment difference of 3.59 (95 \% Cl 0.98; 
6.21; $p=0.0072$ ). Burden and efficacy subscores were also significantly higher in the stepwise group, whereas categories relating to work and life productivity did not differ between the groups.

\section{Patient-managed Insulin Titration}

The FullSTEP study has thus demonstrated that stepwise addition of bolus insulin to basal insulin therapy is non-inferior to direct transition to full basal-bolus therapy in terms of change in $\mathrm{HbA}_{1 c^{\prime}}$ and is associated with lower rates of hypoglycaemia and greater patient satisfaction in comparison with direct transition..$^{18}$ To our knowledge, it remains the only study to have compared these two approaches to insulin intensification using patient-led dose titration.

Since FullSTEP, two RCTs have provided further data to support the concept of patient-led insulin intensification (see Table 1). The START study by Harris et al..$^{52}$ investigated basal-plus therapy in patients previously using basal insulin. It compared patient-led versus physician-managed titration of a single bolus dose of insulin glulisine added at breakfast; patients in the self-managed group adjusted doses by $1 \mathrm{U} /$ day to reach a target 2-hour PPG level between 5.0 and $8.0 \mathrm{mmol} / \mathrm{l}$ (90 and $144 \mathrm{mg} / \mathrm{dl}$ ) (see Table 1) Self-titration was non-inferior to physician-led management; $28.4 \%$ of patients in the self-managed group versus $21.2 \%$ in the physician-led group reached $\mathrm{HbA}_{1 \mathrm{c}} \leq 7 \%$. Quality of life was 'high' in both groups, but the low rates of reaching target reinforce that basal-plus therapy with a single prandial injection is inadequate for many patients to achieve good glycaemic control after the failure of basal-only insulin therapy. ${ }^{52}$

Finally, in the 24-week Study of Insulin Lispro in Participants With Inadequately Controlled Type 2 Diabetes (AUTONOMY) study, Edelman and colleagues compared two approaches to patient-led titration of bolus insulin lispro. ${ }^{53}$ Two frequencies of SMBG measurements and dose titration were compared: a daily schedule and a 3-day schedule, each with a separate titration algorithm (see Table 1). In both groups, bolus doses were added in a stepwise manner, at investigator discretion, to meals in chronological order. Titration of basal insulin glargine was managed by the physician. The study had a parallel-group design, generating two sets of data each for both groups. The two algorithms were comparable in terms of mean $\mathrm{HbA}_{1 \mathrm{c}}$ reduction (which was between $-0.92 \%$ and $-1.00 \%$ in the four data sets) and hypoglycaemia rates, suggesting that daily and 3-day dose adjustment schedules are equivalent. The study report contains no information on patient-reported outcomes or quality-of-life measures..$^{53}$

\section{Summary and Conclusions}

Amid a paucity of evidence to guide intensification of insulin therapy, intensification is frequently undertaken later than indicated. ${ }^{11}$ Such delay risks exacerbating the long-term consequences of T2D. Although guidelines are clear on the need for timely treatment intensification, clinicians have been hampered by a lack of evidence to guide insulin intensification strategies in practice. Enabling self-titration of insulin regimens is particularly important in primary care settings, both to reduce demands on healthcare systems and to increase patients' engagement and satisfaction with treatment. ${ }^{37}$

Previous studies have suggested that, when prandial coverage becomes necessary, physician-led stepwise addition and titration of bolus insulin doses is an effective way to intensify basal-only insulin therapy, and that the additional boluses can be added to meals based on the estimated size of the meal. ${ }^{42-47}$ FullSTEP showed that stepwise treatment intensification, using patient-led dose titration under medical supervision and guidance, is noninferior to full basal-bolus therapy in terms of change in $\mathrm{HbA}_{1 \mathrm{c}}$ after 32 weeks, with less hypoglycaemia and greater patient satisfaction compared with full

\section{Figure 1: Glycaemic Control in the FullSTEP Study}

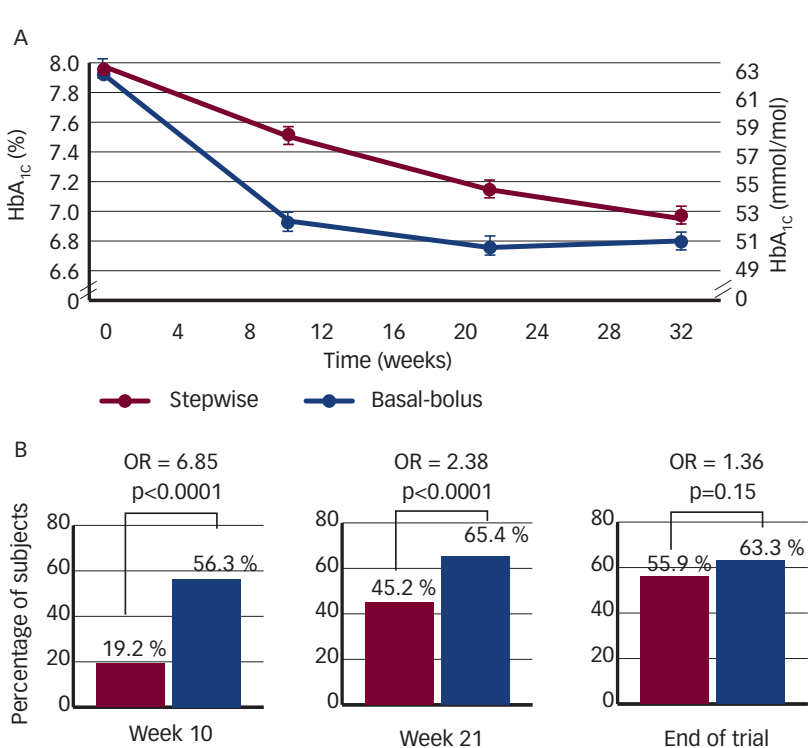

By week 32, there was no significant difference in glycated haemoglobin ( $\left.\mathrm{HbA}_{1}\right)$ reduction between the two approaches (mean treatment difference 0.14; $95 \%$ confidence interval [Cl] -0.03; 0.30; $p=0.0876$ ). A) Observed mean $\mathrm{HbA}$ versus duration after randomisation for both stepwise and basal-bolus groups. B) Patients achieving $\mathrm{HbA}_{1 c}$ target $<7 \%$ (observed percentages and odds ratios [ORs] are estimated from statistical modelling). Reprinted from The Lancet Diabetes \& Endocrinology, Rodbard et al., 2014, ${ }^{18}$ with permission from Elsevier.

\section{Figure 2: Rate of All Treatment-emergent Hypoglycaemic Events by Exposure Week during the FullSTEP Study}

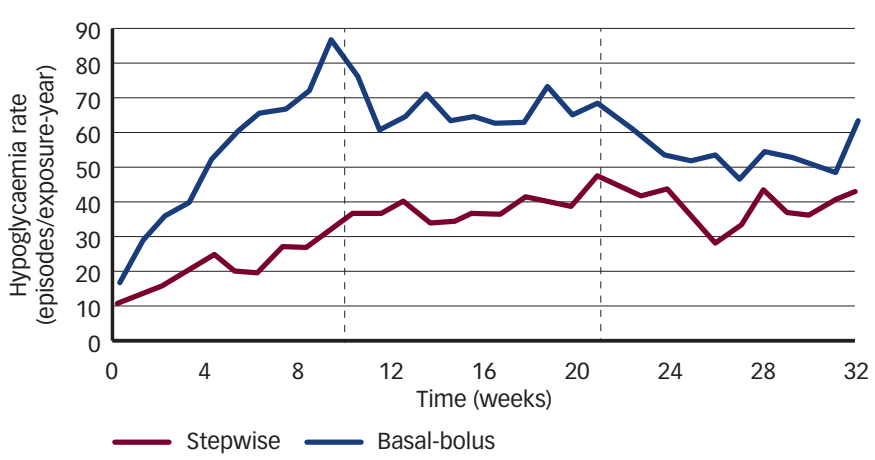

Dotted lines show the time points at which a second and third bolus injection could be added by patients in the stepwise group. The rate of hypog/ycaemia was significantly lower with the stepwise approach than in the basal-bolus group, whether measured at week 11,21 or 32

Reprinted from The Lancet Diabetes \& Endocrinology, Rodbard et al., 2014, ${ }^{18}$ with permission from Elsevier.

basal-bolus therapy (also using patient-led dose titration)..$^{18}$ The easy-to-use '1-0-1' titration algorithm and straightforward approach may reduce the inertia toward treatment intensification that can occur in clinical practice.

Physicians will be reassured that the stepwise intensification approach confers efficacy equivalent to that of full basal-bolus therapy, and that, with appropriate guidance, patients can manage the titration process. Offering patients specific guidance on how to adjust their treatment might increase their sense of empowerment, and mitigate psychological barriers to insulin intensification. Alongside other recent data that support patient-led approaches, these findings will assist physicians and patients in making individualised decisions about the intensification of insulin treatment. 
1. Inzucchi SE, Bergenstal RM, Buse JB, et al., Management of hyperglycemia in type 2 diabetes: a patient-centered

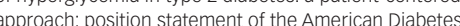
Association (ADA) and the European Association for the Study of Diabetes (EASD), Diabetes Care, 2012;35:1364-79.

2. Rodbard HW, Jellinger PS, Davidson JA, et al., Statement by an American Association of Clinical Endocrinologists/American College of Endocrinology consensus panel on type 2 diabetes mellitus: an algorithm for glycemic control, Endocr Pract, 2009;15:540-59.

3. Home PD, The pharmacokinetics and pharmacodynamics of rapid-acting insulin analogues and their clinical consequences, Diabetes Obes Metab, 2012:14:780-8.

4. Pontiroli AE, Miele L, Morabito A, Metabolic control and risk of hypoglycaemia during the first year of intensive insulin of hypoglycaemia during the first year of intensive insulin analysis, Diabetes Obes Metab, 2012;14:433-46.

5. Cough SC, A review of human and anague insulin Diabetes Res Clin Pract, 2007:77:1-15.

6. Garber AJ, Abrahamson MJ, Barzilay Jl, et al., AACE comprehensive diabetes management algorithm 2013, Endocr Pract, 2013;19:327-36.

7. Garber AJ, Abrahamson MJ, Barzilay Jl, et al., American Association of Clinical Endocrinologists' comprehensive diabetes management algorithm 2013 consensus statementexecutive summary, Endocr Pract, 2013;19:536-57.

8. American Diabetes Association, Standards of medical care in diabetes - 2014, Diabetes Care, 2014;37(Suppl. 1):S14-S80

9. International Diabetes Federation Guideline Development Group, Global guideline for type 2 diabetes, Diabetes Res Clin Pract, 2014:104:1-52.

10. Holden $S E$, Gale EA, Jenkins-Jones S, Currie CJ, How many people inject insulin? UK estimates from 1991 to 2010 Diabetes Obes Metab, 2014:16:553-9.

11. Polinski JM, Connolly JG, Curtis BH, et al., Patterns and trends in insulin intensification among patients with type 2 diabetes: a systematic review, Prim Care Diabetes, 2014;8:101-9.

12. Holman RR, Paul SK, Bethel MA, et al., 10-year follow-up of intensive glucose control in type 2 diabetes, N Engl I Med, 2008:359:1577-89.

13. Nathan DM, The diabetes control and complications trial/ epidemiology of diabetes interventions and complications study at 30 years: overview, Diabetes Care, 2014:37:9-16.

14. Shichiri M, Kishikawa H, Ohkubo Y, Wake N, Long-term results of the Kumamoto Study on optimal diabetes control in type 2 diabetic patients, Diabetes Care, 2000:23(Suppl. 2):B21-B29.

15. Stolar M, Glycemic control and complications in type 2 diabetes mellitus, Am I Med, 2010:123(3 Suppl ):S3-S11. Kunt T, Snoek FJ, Barriers to insulin initiation and

16. Kunt T, Snoek FJ, Barriers to insulin initiation and
intensification and how to overcome them, Int I Clin Pract Suppl, 2009:(164):6-10.

7. Polinski JM, Smith BF, Curtis BH, et al., Barriers to insulin progression among patients with type 2 diabetes: a systematic review, Diabetes Educ, 2013;39:53-65.

18. Rodbard HW, Visco VE, Andersen H, et al., Treatment intensification with stepwise addition of prandial insulin aspart boluses compared with full basal-bolus therapy (FullSTEP Study): a randomised, treat-to-target clinical trial, Lancet Diabetes Endocrinol, 2014;2:30-7.

19. [No authors listed], The effect of intensive treatment of diabetes on the development and progression of long-term complications in insulin-dependent diabetes mellitus The complications in insuling N Engl I Med, 1993:329:977-86.

e blood-glucose control with sulphonylureas or insulin compared with conventional treatment and risk of complications in patients with type 2 diabetes (UKPDS 33). UK Prospective Diabetes Study (UKPDS) Group, Lancet, 1998:352:837-53. Erratum in Lancet, 1999;354:602

21. [No authors listed], Effect of intensive blood-glucose control with metformin on complications in overweight patients with type 2 diabetes (UKPDS 34). UK Prospective Diabetes Study (UKPDS) Group, Lancet, 1998;352:854-65. Erratum in Lancet, 1998; $352: 1558$

22. Chalmers J, Cooper ME, UKPDS and the legacy effect, N Eng/J Med, 2008;359:1618-20.

23. Stratton IM, Adler Al, Neil HA, et al., Association of glycaemia with macrovascular and microvascular complications of type 2 diabetes (UKPDS 35): prospective observational study BMI 2000:321:405-12

24. Akalin S, Berntorp K, Ceriello A, et al., Intensive glucose therapy and clinical implications of recent data: a consensus statement from the Global Task Force on Glycaemic Control, Int I Clin Pract, 2009;63:1421-5.

25. Murray P, Chune GW, Raghavan VA, Legacy effects from DCC and UKPDS: what they mean and implications for future diabetes trials, Curr Atheroscler Rep, 2010;12:432-9.

26. Lind M, Oden A, Fahlen M, Eliasson B, The shape of the metabolic memory of HbA1c: re-analysing the DCCT with respect to time-dependent effects, Diabetologia 2010;53:1093-8.

27. Cavalot $F$, Do data in the literature indicate that glycaemic variability is a clinical problem? Glycaemic variability and vascular complications of diabetes, Diabetes Obes Metab, 2013:15(Suppl. 2):3-8

28. American Diabetes Association, Diagnosis and classification of diabetes mellitus, Diabetes Care, 2014;37(Suppl. 1):S81-S90

29. Monnier L, Lapinski $\mathrm{H}$, Colette $\mathrm{C}$, Contributions of fasting and postprandial plasma glucose increments to the overall diurna hyperglycemia of type 2 diabetic patients: variations with increasing levels of HDA(1C), Diabetes Care, 2003;26:881-5.

30. Monnier L, Colette C, Dunseath GJ, Owens DR, The loss of postprandial glycemic control precedes stepwise deterioration of fasting with worsening diabetes, Diabetes Care, 2007;30:263-9.

31. Gerich JE, Odawara $\mathrm{M}$, Terauchi $\mathrm{Y}$, The rationale for paired preand postprandial self-monitoring of blood glucose: the role of glycemic variability in micro- and macrovascular risk, Curr Med Res Opin, 2007;23:1791-8.

32. Su G, Mi S, Tao H, et al., Association of glycemic variability and the presence and severity of coronary artery disease in patients with type 2 diabetes, Cardiovasc Diabetol, 2011:10:19.

33. Holman RR, Thorne KI, Farmer AJ, et al., Addition of biphasic, prandial, or basal insulin to oral therapy in type 2 diabetes, N Eng/J Med, 2007;357:1716-30.

34. Holman RR, Farmer AJ, Davies MJ, et al., Three-year efficacy of complex insulin regimens in type 2 diabetes, N Engl J Med 2009;361:1736-47.

35. Owens DR, Clinical evidence for the earlier initiation of insulin therapy in type 2 diabetes, Diabetes Technol Ther, 2013;15:776-85

36. Peyrot M, Rubin RR, Lauritzen T, et al., Resistance to insulin therapy among patients and providers: results of the crossnational Diabetes Attitudes, Wishes, and Needs (DAWN) study, Diabetes Care, 2005;28:2673-9.

37. Khunti K, Davies MJ, Kalra S, Self-titration of insulin in the management of people with type 2 diabetes: a practical solution to improve management in primary care, Diabetes Obes Metab, 2013;15:690-700.

38. LaSalle IR Empowering patients during insulin initiation: real-world approach, J Am Osteopath Assoc, 2010;110:69-78.
39. Polonsky WH, Fisher L, Hessler D, Edelman SV, What is so tough about self-monitoring of blood glucose? Perceived obstacles among patients with type 2 diabetes, Diabet Med, 2014;31:40-6.

40. Davies MJ, Gagliardino JJ, Gray LJ, et al., Real-world factors affecting adherence to insulin therapy in patients with type or type 2 diabetes mellitus: a systematic review, Diabet Med, 2013;30:512-24

41. Ampudia-Blasco FJ, Rossetti P, Ascaso JF, Basal plus basalbolus approach in type 2 diabetes, Diabetes Technol Ther 2011;13(Suppl. 1):S75-S83

42. Owens DR, Luzio SD, Sert-Langeron C, Riddle MC, Effects of initiation and titration of a single pre-prandial dose of insulin glulisine while continuing titrated insulin glargine in type 2 diabetes: a 6-month 'proof-of-concept' study, Diabetes Obes Metab, 2011:13:1020-7.

43. Meneghini $L$, Mersebach $H$, Kumar $S$, et al., Comparison of 2 intensification regimens with rapid-acting insulin aspart in type 2 diabetes mellitus inadequately controlled by once-daily insulin detemir and oral antidiabetes drugs: the step-wis randomized study, Endocr Pract, 2011;17:727-36.

44. Meneghini LF, Intensifying insulin therapy: what options are available to patients with type 2 diabetes?, Am J Med 2013;126(9 Suppl. 1):S28-S37.

45. Owens DR, Stepwise intensification of insulin therapy in type 2 diabetes management - exploring the concept of the basalplus approach in clinical practice, Diabet Med, 2013:30:276-88.

46. Raccah D, Bretzel RG, Owens D, Riddle M, When basal insulin therapy in type 2 diabetes mellitus is not enough--what next? Diabetes Metab Res Rev, 2007:23:257-64.

47. Raccah D, Haak TJ, Huet D, et al. Comparison of stepwise addition of prandial insulin to a basal-bolus regimen when basal insulin is insufficient for glycaemic control in type 2 diabetes: results of the OSIRIS study, Diabetes Metab 2012;38:507-14.

48. Davidson MB, Raskin P, Tanenberg RJ, et al., A stepwise approach to insulin therapy in patients with type 2 diabetes mellitus and basal insulin treatment failure, Endocr Pract, 2011;17:395-403.

49. Riddle MC, Rosenstock J, Vlajnic A, Gao L, Randomized, 1-year comparison of three ways to initiate and advance insulin for type 2 diabetes: twice-daily premixed insulin versus basal insulin with either basal-plus one prandial insulin or basabolus up to three prandial injections, Diabetes Obes Metab 2013;16:396-402.

50. US Department of Health and Human Services Food and Drug Administration Center for Drug Evaluation and Research (CDER), Guidance for industry. Diabetes mellitus: developing drugs and therapeutic biologics for treatment and prevention. Available at: http://www.fda.gov/drugs/ guidancecomplianceregulatoryinformation/guidances/ ucm064981.htm (accessed August 2014).

51. Brod M, Skovlund SE, Wittrup-Jensen KU, Measuring the impact of diabetes through patient report of treatment satisfaction, productivity and symptom experience, Qual Life Res, 2006;15:481-91.

52. Harris SB, Yale JF, Berard L, et al., Does a patient-managed insulin intensification strategy with insulin glargine and insulin glulisine provide similar glycemic control as a physicianmanaged strategy? Results of the START (Self-Titration With Apidra to Reach Target) Study: a randomized noninferiority trial, Diabetes Care, 2014:37:604-10.

53. Edelman SV LiU R, Johnson J Glass LC, AUTONOMY the first randomized trial comparing two patient-driven approaches o initiate and titrate prandial insulin lispro in type 2 diabetes, Diabetes Care, 2014;37:2132-40. 